\title{
Entrepreneurial Intention and Outcome Expectancy: Evidence from South Korea and China
}

\author{
Zhou Jiang \\ Central Queensland University \& Macquarie University \\ E-Mail: z.jiang@cqu.edu.au \\ Zhongmin Wang \\ The University of Newcastle \\ E-Mail: aaron.zhongminwang@gmail.com
}

\begin{abstract}
Focusing on the East Asian context, this study examines (1) cultural and gender differences in entrepreneurial intention, (2) the mediating effects of culture and gender on the relationships between entrepreneurial intention and expectancies of positive entrepreneurial outcomes, and (3) the results of entrepreneurial intention of females. The findings reveal that while Chinese students have a greater entrepreneurial intention than South Korean students, the relationships between entrepreneurial intention and outcome expectancies are stronger in South Korean than in Chinese students. In terms of gender, males have a greater entrepreneurial intention than females. The relationships between entrepreneurial intention and outcome expectancies are stronger in male than in female students. Social status and selfrealization are the entrepreneurial outcomes that females value most.
\end{abstract}

Keywords: Entrepreneurial Intention, Desired Entrepreneurial Outcomes, Cultural Difference, Gender Difference

\section{INTRODUCTION}

Entrepreneurial intention arguably plays an important role in the decision to create a business (Liñán \& Chen, 2009). Research has shown that many factors such as need for achievement, propensity to take risk, tolerance for ambiguity, locus of control, self-efficacy, and egoistic passion, can affect a person's intention to engage in entrepreneurial activities, (Shane, Locke, \& Collins, 2003). These motivational factors 
for entrepreneurship have also been suggested to vary among human groups (Haus, Steinmetz, Isidor, \& Kabst, 2013; Liñán \& Chen, 2009). Although this stream of research has contributed to the entrepreneurial literature, several areas need to be improved.

The first area is the focus. Although most of the research on entrepreneurial motivation research focuses on the influence of motivational factors on entrepreneurial intention, only a few studies (e.g., Gatewood, 1993; Manolova, Brush, \& Edelman, 2008) have specifically examined the extent to which a person's entrepreneurial intentions predict his or her valued outcomes of entrepreneurship. Although desired outcomes are considered to be components of motivation in entrepreneurship (Shane et al., 2003), further investigations of what outcomes are expected among people with different degrees of entrepreneurial intention will provide additional perspectives on entrepreneurial motivations (Gatewood, Shaver, Powers, \& Gartner, 2002; Manolova et al., 2008).

The second area is the body of evidence. The current literature on entrepreneurial motivation needs more extensive cross-cultural evidence (Verheul, Stel, \& Thurik, 2006). Among the studies in this area, the majority compared countries from different cultural clusters (for society cluster classification, see Gupta, Hanges, \& Dorfman, 2002). For example, Liñán, Nabi, and Krueger (2013), who investigated undergraduates from Spain (a Latin European culture) and Britain (an Anglo-Saxon culture), found that while personal attitudes have a stronger effect on entrepreneurial intention in Spain, the perceived behavioral control is more likely to influence entrepreneurial intention in Britain. In another study, Liñán and Chen (2009) showed that the motivations of entrepreneurial intention differed in Spain and Taiwan (a Confucian Asian culture). However, it remains unclear whether and how the motivations, and by extension, the desired outcomes, for entrepreneurial-oriented individuals differ among countries from the same cultural cluster.

The third area is gender issues in entrepreneurial intention studies. More women than ever are now choosing entrepreneurship as a career (Jalbert, 2000). Wilson, Kickul, and Marlino (2007) argue that the current trends mask the worldwide tendency for men to have a more entrepreneurial orientation than women. Given that numerous studies still demonstrate a higher entrepreneurial intention among men than among women (e.g., Gupta, Turban, Wasti, \& Sikdar, 2009), an important question is whether women with such intention have higher outcome expectancies that motivate them to engage in entrepreneurship than men do (Manolova et al., 2008). Although Manolova et al.'s (2008) study of businessmen suggests that men and women differ 
only slightly in their outcome expectancies, no firmer conclusion can be drawn without further evidence from different samples.

Fourth, studies conducted in Eastern cultures are relatively rare. Most entrepreneurial research has been conducted in Western societies, though a few scholars have included Eastern countries in their cross-cultural investigations (Liñán \& Chen, 2009; Pruett, Shinnar, Toney, Llopis, \& Fox, 2009). Due to shortage of scholarship despite the urgent need for research, it is still unknown whether the Western results can be generalized to East Asia.

The present study will close these four gaps in the research. Specifically, this study examines the relationships between entrepreneurial intention and desired outcomes using university student samples from China and South Korea (which to the same cultural cluster) and the roles of national culture and gender in these relationships. Figure 1 depicts the research model, which builds on and extends previous work on the entrepreneurship-outcome framework (e.g., Gatewood, 1993; Gatewood et al., 2002), gender roles (e.g., Manolova et al., 2008), and country differences (e.g., Liñán \& Chen, 2009) in entrepreneurial studies.

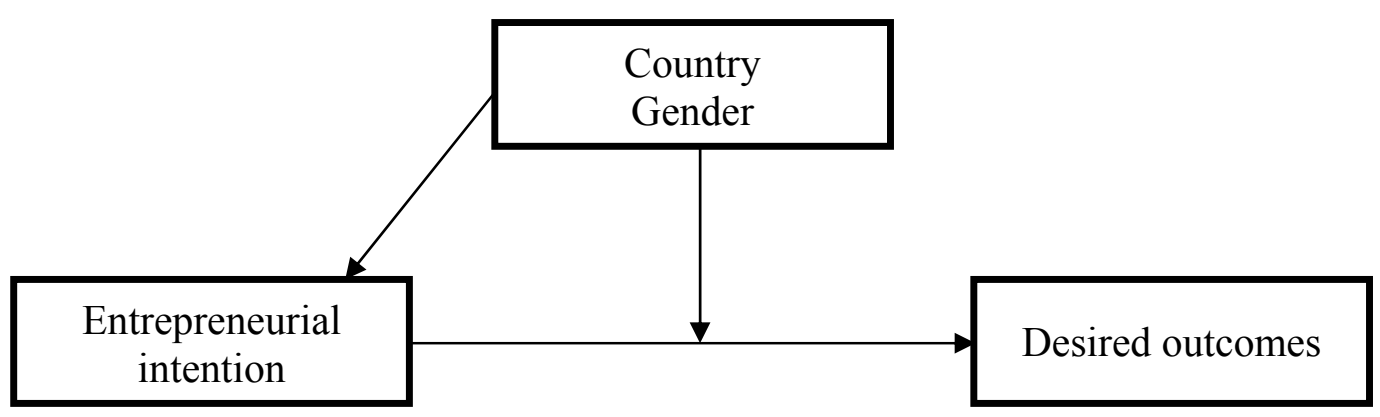

Figure 1 Proposed Research Framework

\section{THEORETICAL BACKGROUND AND HYPOTHESES}

Entrepreneurship is the process of transferring ideas into business and adding value to a combination of resources (Lee, Lim, Lim, $\mathrm{Ng}, \&$ Wong, 2012). In the business world, entrepreneurs use social and environment resources, and create job opportunities (Hisrich, Peters, \& Shepherd, 2005). The course of entrepreneurship is full of challenges, difficulties, uncertainties, and risks. Entrepreneurial intention and behavior are two necessary phases of entrepreneurship. Entrepreneurial intention is the conscious state of mind directing personal experience, attention, and behavior toward entrepreneurial behaviors (Bird, 1988). It is the first step in the process of 
venture creation (Lee \& Wong, 2004) and a necessary precursor to engaging in entrepreneurial activities (Liñán \& Chen, 2009). Contemporary entrepreneurship research has identified entrepreneurial intention as the strongest predictor of entrepreneurial activity (Krueger, Reilly, \& Carsrud, 2000).

According to intention models, entrepreneurial behaviors are planned and reflect cognitive processing, in which people use knowledge, experience, attitudes, and beliefs to promote the evolution of their intentions (Krueger et al., 2000). Entrepreneurship involves both opportunity and uncertainty or risk (Wennekers, Thurik, Stel, \& Noorderhaven, 2007). A person's decisions to choose entrepreneurial careers tend to be greatly influenced by the extent to which he or she values these two factors in processing cognition. Based on creation theory (Alvarez \& Barney, 2007), opportunities are inherently evolutionary, changing with the cognitions, intentions, and actions of decision makers. Opportunities, characterized by ambiguity and uncertainty, are created, grown, and destroyed by evolutionary processes. People intending to engage in entrepreneurship expect to face uncertainty and ambiguity as they exploit opportunities (Alvarez \& Barney, 2007; Jackson, 2010). Creation theory suggests an opportunity-uncertainty framework in entrepreneurship, reflecting the human tendency to be involved in the evolution from uncertainty to opportunity (Jackson, 2010). It has been suggested that people who are more willing, or able, to take advantage of uncertainties are more likely to have an entrepreneurial spirit and thus to value opportunities and their outcomes (Swierczek \& Ha, 2003), perhaps because of their greater confidence in assessing uncertainty-opportunity evolutionary processes. Research indicates that people's ways of measuring, and their preferences for, opportunity and the uncertainty depend upon their personal traits and social factors (Mueller \& Thomas, 2001). This variation may lead to different decisions being made about and different expectations being held of entrepreneurship. In the following sections, we use this uncertainty-opportunity framework to explain the influences of culture and gender on entrepreneurial intention and outcome expectancies from entrepreneurship.

\section{The Role of Culture}

People from different cultural backgrounds tend to have different cognitions (Hofstede, 2001), which may cause inconsistencies in their intentions. Although the two East Asian countries of China and South Korea are usually placed within the same cultural cluster, each has its own cultural nuances, some of which have been identified by Hofstede's (2001) cultural dimensions. The dimension capturing most systematic differences between China and South Korea is uncertainty avoidance, on which South 
Koreans generally score higher than Chinese (Hofstede, 2001). Uncertainty avoidance reflects the extent to which members of a cultural group feel either comfortable or uncomfortable in unstructured situations (Hofstede, 2001). A decision to start up a new venture is one such situation, since it is unknown, surprising, novel, or different from the typical career path. Research has consistently shown that uncertainty avoidance is highly relevant in explaining cultural differences in entrepreneurial issues (Gupta, MacMillan, \& Surie, 2004; Thomas \& Mueller, 2000).

According to Hofstede (2001), in low uncertainty avoidance cultures, people tend to confront uncertainties, to take risks, and to identify opportunities. In such cultures, pioneering efforts are regarded as the drivers of achievements (Mueller \& Thomas, 2001). In contrast, in high uncertainty avoidance cultures, people expect minimal uncertainty, which they prefer to ignore or overlook. People holding unconventional attitudes and behaviors (e.g., wishing to start a new venture) are likely to be viewed with suspicion. In these societies, security is valued, and is considered an achievement (Mueller \& Thomas, 2001).

Cultures with low uncertainty avoidance (or high uncertainty acceptance) have a greater tendency to accept non-traditional behaviors. In some of these cultures, people are encouraged to explore opportunities despite the uncertainties and risks (Mueller \& Thomas, 2001). Entrepreneurs, or potential entrepreneurs, in these societies experience greater legitimacy and freedom, and they have a stronger motivation to engage in new business than do their counterparts from high uncertainty avoidance cultures. Indeed, empirical entrepreneurial research has consistently supported the role of uncertainty avoidance. For example, Muller and Thomas (2001) investigated university students from 15 countries and found that students from low, not high, uncertainty avoidance cultures reported a greater entrepreneurial orientation. Focusing on Vietnam and Thailand, Swierczek and Ha (2003) found that the Vietnamese, who tend to have lower uncertainty avoidance than their Thai counterparts (Hofstede, 2001), are more inclined to be risk-taking, which is one dimension of entrepreneurial orientation (Swierczek \& Ha, 2003). In line with our discussion and the previous findings, we expect people from China to show greater interest in entrepreneurship than people from South Korea.

H1. Chinese students have a greater entrepreneurial intention than Korean students.

A person's intention to become an entrepreneur is driven by certain forces such as attainment of personal experiences or accomplishment of target goals (Hisrich et al., 2005). In other words, people start a new business partially because they desire 
rewards from entrepreneurial behaviors. As an extension of Carter, Gartner, and Shaver's (2004) research, Manaolova et al. (2008) identified four types of desired outcomes that are particularly relevant to entrepreneurship: self-realization, social status, financial success, and autonomy. They found that US entrepreneurs' desire to start a business significantly predicts their pursuit of these desired outcomes. However, because the intention of choosing entrepreneurial careers may also be affected by other factors, such as values, wants, needs, beliefs, and habits (Bird, 1988; Lee \& Wong, 2004), it is possible that their desires for entrepreneurial outcomes are affected by their cultural background. As discussed previously, South Koreans are less tolerant of uncertainty and ambiguity in making career decisions than Chinese are. For people from uncertainty-avoiding cultures to have greater intentions to engage in entrepreneurship, which entails high risk, the incentives need to be attractive enough for their cognition to focus on the opportunities rather than on the uncertainties of entrepreneurship. This contention is supported by Begley and Tan's (2001) crosscultural study of entrepreneurial interest and expectations. They classified ten countries into Anglo-Saxon and East Asian cultural groups, reflecting lower (average score $=48$ ) and higher (average score $=53$ ) uncertainty avoidance cultures, respectively (Hofstede, 2001). Their findings suggested that the East Asian group had higher expectations of their entrepreneurial interests. Logically extending this finding to our research, in which China and South Korea are characterized by lower and higher levels of uncertainty avoidance, respectively, it may be expected that South Koreans, having greater entrepreneurial intentions, may exhibit a stronger desire for positive entrepreneurial outcomes than their Chinese counterparts. Thus, it is hypothesized:

H2. Compared to Chinese students, Korean students with greater entrepreneurial intentions have greater expectancies of desired outcomes.

\section{The Role of Gender}

Males have long been the majority of entrepreneurs. However, with the steady increase in the number of female entrepreneurs, an increasing body of research has investigated the role of gender in entrepreneurial processes (Haus et al., 2013). The literature has shown mixed results regarding gender differences in entrepreneurial intentions. While several studies have detected significant gender differences (e.g., Zhao, Seibert, \& Hills, 2005), others have detected none (e.g., Gupta et al., 2009). These inconsistent findings warrant further investigations under different contexts or using different samples, , so as to advance the knowledge of gender roles in entrepreneurial issues (Ahl, 2006). 
According to the role-congruity theory (Eagly \& Karau, 2002), males and females match their behaviors, such as creating a business, with the attributes and characteristics perceived necessary for success (Haus et al., 2013). Entrepreneurship requires people to be aggressive, achievement-oriented, independent, tolerant of high risk, assertive, and willing to accept challenges (Haus et al., 2013). It has been revealed that males are more likely than females to possess these attributes, which are regarded as beneficial to the processes of entrepreneurship (Gupta et al., 2009). Additionally, males, especially those in Asian countries, usually encounter fewer barriers and enjoy greater social and family support than their female counterparts do (Kobeissi, 2010). Consequently, males tend to be more optimistic and confident when facing the uncertainties of starting a business; they also tend to assign greater value to opportunities. In contrast, females tend to be reluctant to enter situations with risks and uncertain prospects of success (Haus et al., 2013; Orobia, Sserwanga, \& Rooks, 2011). Kang and Wong's (2004) investigation of Singapore university students supported this prediction, showing that female students reported less interest in entrepreneurialism than male students. Similar results were found in other Asian countries such as China (Shinnar, Giacomin, \& Janssen, 2012) and Malaysia (Sandhu, Sidique, \& Riaz, 2011). Thus, we expect to find that entrepreneurship is more attractive to males than to females.

H3. Male students have a greater entrepreneurial intention than female students.

As discussed above, females might engage in entrepreneurial activities less than males, partly due to their reluctance or lack of confidence to engage in problem solving or coping with risks and uncertainties (Langowitz \& Minniti, 2007). It is likely that only when their desire for positive entrepreneurial outcomes is strong enough to overcome their concerns about the uncertain situations that females consider starting a business. In other words, female (potential) entrepreneurs might need greater incentives than males do to motivate themselves, paying greater attention to their expected outcomes from entrepreneurship. In turn, females with greater entrepreneurial intentions tend to pursue the desired entrepreneurial outcomes more aggressively than their male counterparts. In Manolova et al.'s (2008) study, female, not male, entrepreneurs were found to have a significant expectancy of social status. Females were also found to have a stronger expectancy of self-realization than were entrepreneurship than males. Accordingly, we propose:

H4. Female students with greater entrepreneurial intentions have greater expectancies of desired outcomes than male students do. 
In addition, Mau (2000) claims that women in Asian countries have lower social status and are lower in the decision-making hierarchy. They often feel unqualified to make career decisions. In light of this situation, we argue that in our East Asian context, females assign greater importance to social status and to self-realization, both of which may have been suppressed but which they want to pursue in their social life, than they do to other desired outcomes, especially monetary ones (Kobeissi, 2010). Research has suggested that women entrepreneurs tend to be more sensitive to social status and self-realization (Kupferberg, 2003). Therefore, we hypothesize:

H5. Self-realization and social status are more strongly related to entrepreneurial intention than to other desired outcomes for female students.

\section{METHODOLOGY}

\section{Participants}

The participants in this study were Chinese and South Korean university undergraduates. We used student samples because research suggests that university students have become, and will remain a main force in entrepreneurship, so extensive investigation of this population is warranted (Mueller, 2004). A survey was administered at one university in eastern South Korea and at one in central China. These two universities were identified through the authors' professional networks. Each university is among the largest and most respected in its country, with nearly 30,000 full-time students from across the country. Convenience sampling was used to collect the data. Students finished the survey on a voluntary basis as part of a public course on career decisions. A total of 357 usable questionnaires were returned (average response rate $=79.3 \%$ ). Of these, $143(40.1 \%$ ) were from China (response rate $=71.5 \%$ ), and $214(59.9 \%)$, from South Korea (response rate $=85.6 \%)$. The Chinese respondents had a mean age of 19.9 years $(S D=1.69)$, and $50.3 \%$ were males. Twenty-four percent were freshmen, $38.5 \%$ were sophomores, $23.1 \%$ were juniors, $12.6 \%$ were seniors, and $1.4 \%$ did not report their academic year. Thirty-five percent majored in sciences, $40.6 \%$ in social sciences, $16.1 \%$ in arts and human sciences, $6.3 \%$ in other subjects, and $2.1 \%$ did not report. The Korean respondents had a mean age of 20.4 years $(\mathrm{SD}=1.84)$, and $51.4 \%$ were males. Thirty percent were freshmen, $31.8 \%$ were sophomores, $23.1 \%$ were juniors, $13.1 \%$ were seniors, and $2.8 \%$ did not report their academic levels. Forty-two percent majored in sciences, $42.5 \%$ in social sciences, $7.9 \%$ in arts and human sciences, $3.7 \%$ in other subjects, and $3.7 \%$ did not report. 


\section{Measures}

The English questionnaire was translated into Chinese and Korean versions through the use of back-translation methods (Brislin, 1980). Two language experts knowing both Chinese and Korean also checked the two translated versions of the questionnaire. Little ambiguity was found, and all the items were understandable and interpretable in Chinese and Korean. The meanings and concepts of these items were also found to be consistent between the two translated versions in the languagechecking process. All items of the measurements were answered based on a Likerttype scale ranging from " 1 = strongly disagree" to " 7 = strongly agree."

\section{Entrepreneurial intention}

Liñán and Chen's (2009) six-item scale was used to measure university students' intentions to engage in entrepreneurial activities. A sample item was "I have the firm intention to start a business someday." Higher scores indicated greater entrepreneurial intentions. Analyses of variance (ANOVA) were employed to examine whether the construct of entrepreneurial intention was equivalent across Chinese and Korean groups (Leung \& Zhou, 2008). Two items were significantly $(\mathrm{p}<.05)$ affected by the interaction between country and the total score of entrepreneurial intention. That is, these two items were not at all equivalent between China and South Korea. Thus, they were excluded from further analyses.

\section{Desired outcomes}

The scales developed by Manolova et al. (2008) were adapted to measure the four desired outcomes from entrepreneurial activities. Respondents were asked the extent to which they agreed or disagreed that a series of listed items (each item offered one reason) were important for entrepreneurs to start a new business. Higher scores reflected greater desires for corresponding outcomes. The scale for self-realization consisted of seven items, such as "to achieve something and get recognition." The scale for social status consisted of four items, such as "to achieve a higher position in society." The scale for financial success consisted of four items, such as "to earn larger personal income." The scale for autonomy consisted of three items, such as "to have greater flexibility for personal and family life." Since results of ANOVA indicated that none of the three items for autonomy were equivalent between China and South Korea, autonomy was excluded from further analyses. For the same reason (i.e., lack of cross-cultural equivalence), two items for self-realization and one item for social status were deleted. 


\section{Analyses}

Confirmatory factor analyses (CFA) were performed to examine the validity of the measurement model, followed by multi-group CFA, which was used to reconfirm the cross-cultural equivalence of the measures (Blunch, 2008). $T$ tests were conducted for $\mathrm{H} 1$ and $\mathrm{H} 3$. Hierarchical regression analyses were conducted to test $\mathrm{H} 2$ and $\mathrm{H} 4$; subsets were entered into the following equations: (1) country or gender, (2) entrepreneurial intention, and (3) interaction by entrepreneurial intention and country or gender. A moderating effect existed if the additional $R$ square for the interaction was significant. To support the hypotheses, the slopes of interactions had to be in the predicted direction. Correlation differences were examined to test H5.

\section{RESULTS}

Results of CFA on the retained 16 items showed that the four-factor measurement model (entrepreneurial intention, self-realization expectancy, social status expectancy, and financial success expectancy) fit the data well ( $\chi 2=349.625$, $\mathrm{df}$ $=98, \mathrm{SRMR}=.045, \mathrm{GFI}=.877, \mathrm{AGFI}=.829, \mathrm{RMSEA}=.085, \mathrm{CFI}=.941)$, suggesting a good discriminant validity. For all four factors, the value of average variance extracted (AVE) was greater than .500, and the composite reliability (CR) value was greater than the corresponding AVE (entrepreneurial intention: AVE $=.584, \mathrm{CR}=.762$; self-realization: $\mathrm{AVE}=.591, \mathrm{CR}=.628$; social status: $\mathrm{AVE}$ $=.643, \mathrm{CR}=.748$; and financial success: $\mathrm{AVE}=.810, \mathrm{CR}=.830)$. Therefore, the convergent validity of the constructs was confirmed (Hair, Black, Babin, \& Anderson, 2010). Compared with the four-factor model, the single-factor model fit the data much more poorly $(\chi 2=1363.673, \mathrm{df}=104, \mathrm{SRMR}=.094, \mathrm{GFI}=.598$, AGFI $=.475$, RMSEA $=.184$, CFI $=.703$ ), indicating that common method biases were not significant in this study. Results of multi-group CFA showed that the constructs were equivalent across China and South Korea at the configural $(\chi 2=532.370$, df $=196$, $\mathrm{SRMR}=.089, \mathrm{GFI}=.831, \mathrm{AGFI}=.765, \mathrm{RMSEA}=.070, \mathrm{CFI}=.913)$ and metric $(\chi 2$ $=543.102, \mathrm{df}=208, \mathrm{SRMR}=.086, \mathrm{GFI}=.829, \mathrm{AGFI}=.776, \mathrm{RMSEA}=.067, \mathrm{CFI}$ $=.913$ ) levels. Thus, the data collected from China and South Korea can be legitimately combined to test relationships among the estimated measures. Table 1 presents means, standard deviations, reliabilities, and correlations of the variables.

The results of the $t$ test showed that the Chinese reported significantly higher scores on entrepreneurial intention $(M=4.81, S D=1.52)$ than the Koreans $(M=3.44$, $S D=1.67), t(355)=7.91, p<.001$. Thus, H1 was supported. Results of hierarchical regression (see Table 2) showed that the interaction by entrepreneurial intention and country (South Korea $=0$ and China $=1$ ) was negatively and significantly related to 
social status and financial success, but there was no significant impact on the expectancy of self-realization. Specifically, country negatively moderated the relationships of entrepreneurial intention with social status and financial success, such that these relationships were stronger in Korean students than in their Chinese counterparts. However, the relationship between entrepreneurial intention and selfrealization was not moderated by country. Thus, $\mathrm{H} 2$ was partially supported.

Table 1 Means, Standard Deviations, Correlations, and Reliability Coefficients

\begin{tabular}{lllllll}
\hline Variables & Mean & SD & 1 & 2 & 3 & 4 \\
\hline China & & & & & & \\
1. Entrepreneurial intention & 4.81 & 1.52 & $(.93)$ & & & \\
2. Expectancy of self-realization & 5.21 & .98 & $.51^{* *}$ & $(.82)$ & & \\
3. Expectancy of social status & 5.32 & 1.06 & $.53^{* *}$ & $.52^{* *}$ & $(.73)^{* *}$ & \\
4. Expectancy of financial success & 5.43 & .98 & $.41^{* *}$ & $.55^{* *}$ & $.60^{* *}$ & $(.76)$ \\
& & & & & & \\
South Korea & & & & & & \\
1. Entrepreneurial intention & 3.44 & 1.67 & $(.93)^{* *}$ & & & \\
2. Expectancy of self-realization & 4.63 & 1.29 & $.55^{* *}$ & $(.89)$ & & \\
3. Expectancy of social status & 4.40 & 1.39 & $.60^{* *}$ & $.72^{* *}$ & $(.80)$ & \\
4. Expectancy of financial success & 4.43 & 1.36 & $.53^{* *}$ & $.61^{* *}$ & $.72^{* *}$ & $(.89)$ \\
\hline
\end{tabular}

Note: Reliabilities are in the parentheses.

${ }^{* *} p<.01$.

Table 2 Hierarchical Regression for Moderating Effects of Culture and Gender

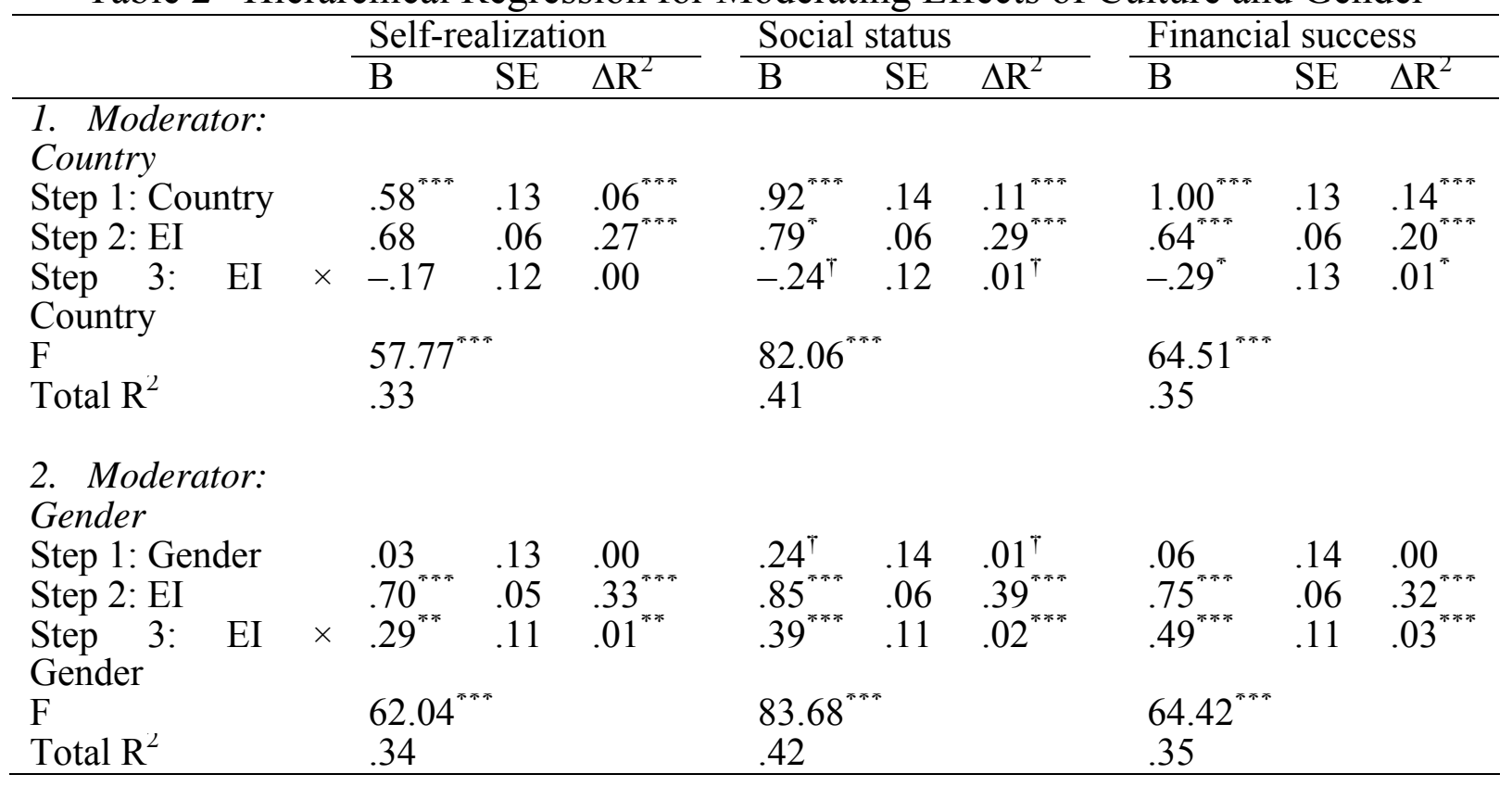

Note: Unstandardized coefficients are reported. $\mathrm{EI}=$ entrepreneurial intention. Country: South Korea $=0 ;$ China $=1$. Gender: female $=0 ;$ male $=1$.

${ }^{\dagger} p<.10 .{ }^{*} p<.05 .^{* *} p<.01 .^{* * *} p<.001$. 
A $t$ test for the mean difference showed that males $(M=4.23, S D=1.77)$ had a greater entrepreneurial intention than females $(M=3.71, S D=1.69), t(355)=2.99, p$ $<0.01$, supporting H3. Hierarchical regression results (see Table 2) demonstrated that gender (female $=0$ and male $=1$ ) moderated the relationships of entrepreneurial intention with self-realization, social status, and financial success. As the interaction by entrepreneurial intention and gender had a positive regression coefficient for all three desired outcomes, the relationships between entrepreneurial intention and these desired outcomes were stronger in males than in females. In light of these contradictory results, H4 was not supported.

To test H5, we ran correlational analyses for the female group $(N=175)$ and used Fisher $z$-transformation to compare the differences between correlations of entrepreneurial intention with the three desired outcomes. Results showed that for females, entrepreneurial intention's relationships with self-realization $(r=.49, \mathrm{p}$ $<.001)$ and social status $(r=.53, \mathrm{p}<.001)$ were stronger than its relationship with financial success $(r=.41, \mathrm{p}<.001)$; z-transformation differences were $1.90, p<.05$, one-tailed and $2.85, p<.05$, one-tailed, respectively. Thus, H5 was supported.

\section{DISCUSSION}

Based on the data collected from China and South Korea, this study examined whether or not there are cultural and gender differences in university students' entrepreneurial career intentions and what they desire from entrepreneurial activities. As expected, Chinese students, with greater tolerance for uncertainty, are more willing to start a business than Korean students, who with less tolerance for uncertainty, as identified by Hofstede's (2001) cultural scores. The finding is consistent with previous studies linking entrepreneurship and uncertainty avoidance (e.g., Liñán \& Chen, 2009; Liñán et al., 2013), and verified the proposed uncertainty-opportunity framework that is applied to entrepreneurial research from the perspective of cultural variation. This framework is supported by the finding that Korean students with higher entrepreneurial intentions, rather than similar Chinese students, tend to have a stronger desire for self-realization, social status, and financial success. As we argued previously, people may consciously evaluate the opportunities and uncertainties across the process of entrepreneurship. Our results, to a certain in line with previous crosscultural studies (e.g., Begley \& Tan, 2001; Gupta et al., 2004; Pruett et al., 2009), suggest that, in general, people from uncertainty-accepting cultures have positive attitudes toward opportunities and thus are less motivated by expected results from entrepreneurial success. In contrast, those from uncertainty-avoiding cultures may, 
once they form the intention to start a business, expect more from entrepreneurship to alleviate the concerns caused by uncertainties in risky situations.

The entrepreneurial opportunity-uncertainty perspective is also supported by the gender differences detected in university students' entrepreneurial intentions. Specifically, male students scored higher than their female counterparts in the intention to start up a business, because males possessed the attributes and characteristics related to entrepreneurship (e.g., being achievement- and goaloriented), which may have given them greater confidence and encouraged them to concentrate on finding opportunities in uncertainties. This result is consistent with Zhao et al.'s (2005) finding that men tend to have higher entrepreneurial intentions than women do. However, although gender differences emerge in the relationships between entrepreneurial intention and individuals' desired outcomes, the differences are not consistent with the opportunity-uncertainty perspective in that these relationships were found to be stronger in men than in women. Although the reasons for this inconsistency cannot be confirmed without further evidence, previous research has provided potential explanations (Kobeissi, 2010). Minniti and Arenius (2003) argued that entrepreneurship was driven mainly by opportunity or by necessity, and that necessity-driven entrepreneurship is more prevalent in non-Western countries (Desai, 2009; Minniti \& Arenius, 2003). Tambunan (2009) found that relative to their male counterparts, female entrepreneurs in Asian countries are more influenced by necessity or "push" factors such as unemployment, poverty, or a need for money. As all three factors examined in the present study are closer to opportunity factors than to necessity factors, the findings that contradict our hypotheses might be attributed to Asian women's general focus on necessity factors. Future research should verify this finding by exploring the role of gender in other contexts and situations based on the opportunity-uncertainty framework.

In addition, our findings regarding women's expectations of entrepreneurship suggest that the most likely reasons for female Asian students to engage in venture creation are desires for social status and self-realization. The findings largely reflect Mau's (2000) argument that for Asian women, these desires have been suppressed by social pressures or traditional values, which partly explains the tendency for women entrepreneurs in Asia to seek recognition from themselves and from society. The results are also consistent with Dhaliwal's (2000) study, which suggests that Asian women are, to a larger extent than men, satisfied with their status, relative to financial and economic necessity, even though sometimes they care about necessity factors more than men do (Tambunan, 2009). 
This study has some limitations. First, the single-source data may have caused common method biases. Although the results of CFA showed that these biases are not significant (Podsakoff, MacKenzie, Lee, \& Podsakoff, 2003),future research should use different data sources to minimize common method biases. Second, we were not able to provide evidence on one of the desired entrepreneurial outcomes, autonomy, due to the cross-cultural inequivalence in its construct. Future research should strive to increase the cross-cultural equivalence in variable concepts and constructs, so as to generate more comprehensive and reliable findings to advance our understanding of entrepreneurial outcome expectancies. Third, the attributes of the research design make it difficult to make causal inferences. Further research should explore mediating variables (e.g., entrepreneurial behavior or performance) between entrepreneurial intentions and desired outcomes, and preferably adopt a longitudinal design to investigate the causal relationships in more fine-grained ways.

These limitations are countered by at least two strengths. First, this research provides a new theoretical framework - the entrepreneurial uncertainty-opportunity perspective -- to explain cultural and gender differences in entrepreneurial intentions and outcome expectancy. Although this framework is only partially supported in explaining gender differences, it still offers a useful insight into entrepreneurial issues across different groups. The uncertainty-opportunity framework may be extended to other demographic groups, such as those identified by age and education, which have been shown to influence attitudes toward uncertainty and opportunity (Delmar \& Davidsson, 2000). In addition, it may be applicable when examining other personal and contextual moderators in the entrepreneurial intention and outcome expectancy (or motivation) relationship, given that both personal and contextual factors can affect the ways in which people deal with uncertainties (van den Bos, 2009). Second, this study is among the first to make within-Asian comparisons of entrepreneurial intentions and contributes to the literature by offering insight into the roles of East Asian cultural nuances. Compared to the differences among cultural clusters that have been extensively examined, within-cultural-cluster differences are neglected but are usually important because cultural nuances lead to great discrepancies in people's intentions, attitudes, and behaviors (Hofstede, 2001).

Our study has important practical implications. First, the findings may help managers seeking cooperation on international venture investments to understand how cultural differences may influence potential collaborators' intentions to collaborate with a new business. In an international context, the cultural differences in people's outcome expectancies from entrepreneurship should be considered when identifying prospective members of the top management of a new venture. In fulfilling individual 
expectations, new organizations should be aware that employees from different cultures value a variety of outcomes related to starting and operating a new business to different degrees. For example, Chinese employees may have higher expectations of financial success than their Korean counterparts do. Second, this study reminds managers of the importance of gender differences in employees' expectations of participating in the establishment of a new organization or business. Our findings suggest that in new entrepreneurial organizations, men may be more ambitious than women in pursuing financial success, self-realization, and status. The effects of these implications might be more apparent in the preparatory stage of a new business.

\section{CONCLUSION}

Using survey data from China and South Korea, this study examines how culture, as characterized by Hofstede's (2001) uncertainty avoidance, and gender influence university students' entrepreneurial career intentions, and how culture and gender moderate the relationships between entrepreneurial intention and outcome expectancies. The results showed that individuals from China, a culture with lower uncertainty avoidance have a greater entrepreneurial intention than those from South Korea, a culture with higher uncertainty avoidance. Compared to their South Korean counterparts, Chinese students with greater entrepreneurial intentions tended to exhibit greater expectations of social status and financial success. Regarding gender differences, the results revealed that men generally have greater entrepreneurial intentions than women. Men were more likely than women to have high expectations of self-realization, social status, and financial success. In addition, further analyses indicated that Asian women cared less about financial success and more about social status and self-realization, which they are believed to lack in social and work life (Mau, 2000). These findings not only advance our understanding of the roles of culture and gender in self-employment issues but also suggest that organizations, especially in the preparatory stage, should be more mindful of the cultural and gender differences among employees who perform entrepreneurial tasks.

\section{REFERENCES}

Ahl, H. (2006). Why research on women entrepreneurs needs new directions. Entrepreneurship Theory and Practice, 30(5), 595-621. http://dx.doi.org/10.1111/j.1540-6520.2006.00138.x

Alvarez, S. A., \& Barney, J. B. (2007). Discovery and creation: Alternative theories of entrepreneurial action. Strategic Entrepreneurship Journal, 1(1-2), 11-26. http://dx.doi.org/10.1002/sej.4 
Begley, T. M., \& Tan, W.-L. (2001). The socio-cultural environment for entrepreneurship: A comparison between east asian and anglo-saxon countries. Journal of International Business Studies, 32(3), 537-553. http://dx.doi.org/10.1057/palgrave.jibs.8490983

Bird, B. (1988). Implementing entrepreneurial ideas: The case for intention. Academy of Management Review, 13(3), 442-453. http://dx.doi.org/10.5465/AMR.1988.4306970

Blunch, N. J. (2008). Introduction to structural equation modelling using SPSS and AMOS. Thousand Oaks, CA: Sage Publications.

Brislin, R. W. (1980). Translation and content analysis of oral and written materials. In H. C. Triandis \& J. W. Berry (Eds.), Handbook of cross-cultural psychology (Vol. 2, pp. 389-444). Boston: Allyn \& Bacon.

Carter, N., Gartner, W., \& Shaver, K. (2004). Career reasons. In W. B. Gartner, K. G. Shaver, N. M. Carter \& P. D. Reynolds (Eds.), Handbook of entrepreneurial dynamics: The process of business creation (pp. 142-152). Thousand Oaks, CA: Sage Publications.

Delmar, F., \& Davidsson, P. (2000). Where do they come from? Prevalence and characteristics of nascent entrepreneurs. Entrepreneurship \& Regional Development, 12(1), 1-23. http://dx.doi.org/10.1080/089856200283063

Desai, S. (2009). Measuring entrepreneurship in developing countries. United Nations University World Institute for Development Economics Research. Research Paper No. 2009/10.

Dhaliwal, S. (2000). Entrepreneurship-a learning process: The experiences of asian female entrepreneurs and women in business. Education+ Training, 42(8), 445453. http://dx.doi.org/10.1108/00400910010379970

Eagly, A. H., \& Karau, S. J. (2002). Role congruity theory of prejudice toward female leaders. Psychological Review, 109(3), 573-598. http://dx.doi.org/10.1037/0033295X.109.3.573

Gatewood, E. (1993). The expectancies in public sector venture assistance. Entrepreneurship Theory and Practice, 17, 91-91.

Gatewood, E. J., Shaver, K. G., Powers, J. B., \& Gartner, W. B. (2002). Entrepreneurial expectancy, task effort, and performance. Entrepreneurship Theory and Practice, 27(2), 187-206. http://dx.doi.org/10.1111/1540-8520.00011

Gupta, V., Hanges, P. J., \& Dorfman, P. (2002). Cultural clusters: Methodology and findings. Journal of world business, 37(1), 11-15. http://dx.doi.org/10.1016/S1090-9516(01)00070-0 
Gupta, V., MacMillan, I. C., \& Surie, G. (2004). Entrepreneurial leadership: Developing and measuring a cross-cultural construct. Journal of Business Venturing, 19(2), 241-260. doi: http://dx.doi.org/10.1016/S0883-9026(03)000405

Gupta, V. K., Turban, D. B., Wasti, S. A., \& Sikdar, A. (2009). The role of gender stereotypes in perceptions of entrepreneurs and intentions to become an entrepreneur. Entrepreneurship Theory and Practice, 33(2), 397-417. http://dx.doi.org/10.1111/j.1540-6520.2009.00296.x

Hair, J., Black, W., Babin, B., \& Anderson, R. (2010). Multivariate data analysis (7th ed.). Upper Saddle River: Prentice-Hall.

Haus, I., Steinmetz, H., Isidor, R., \& Kabst, R. (2013). Gender effects on entrepreneurial intention: A meta-analytical structural equation model. International Journal of Gender and Entrepreneurship, 5(2), 130-156. http://dx.doi.org/10.1108/17566261311328828

Hisrich, R., Peters, M., \& Shepherd, D. (2005). Entrepreneurship with OLC. Illinois: McGraw Hill.

Hofstede, G. (2001). Culture's consequences. Thousand Oaks, CA: Sage Publications. Jackson, S. (2010). Mulling over massachusetts: Health insurance mandates and entrepreneurs. Entrepreneurship Theory and Practice, 34(5), 909-931. http://dx.doi.org/10.1111/j.1540-6520.2009.00351.x

Jalbert, S. E. (2000). Women entrepreneurs in the global economy. Washington, DC: Center for International Private Enterprise.

Kobeissi, N. (2010). Gender factors and female entrepreneurship: International evidence and policy implications. Journal of International Entrepreneurship, 8(1), 1-35. http://dx.doi.org/10.1007/s10843-010-0045-y

Krueger, N. F., Reilly, M. D., \& Carsrud, A. L. (2000). Competing models of entrepreneurial intentions. Journal of Business Venturing, 15(5), 411-432. http://dx.doi.org/10.1016/S0883-9026(98)00033-0

Kupferberg, F. (2003). The established and the newcomers: What makes immigrant and women entrepreneurs so special? International Review of Sociology: Revue Internationale de Sociologie, 13(1), 89-104. http://dx.doi.org/10.1080/0390670032000087005

Langowitz, N., \& Minniti, M. (2007). The entrepreneurial propensity of women. Entrepreneurship Theory and Practice, 31(3), 341-364. http://dx.doi.org/ 10.1111/j.1540-6520.2007.00177.x 
Lee, S. H., \& Wong, P. K. (2004). An exploratory study of technopreneurial intentions: A career anchor perspective. Journal of Business Venturing, 19(1), 728. http://dx.doi.org/10.1016/S0883-9026(02)00112-X

Lee, W. N., Lim, B. P., Lim, L. Y., Ng, H. S., \& Wong, J. L. (2012). Entrepreneurial intention: A study among students of higher learning institution. (Unpublished honors thesis). Universiti Tunku Abdul Rahman, Petaling Jaya, Malaysia.

Leung, K., \& Zhou, F. (2008). Methodology for cross-cultural research. In X.-P. Chen, A. S. Tsui \& J.-L. Farh (Eds.), Empirical methods in organization and management research (pp. 385-408). Beijing, China: Peking University Press.

Liñán, F., \& Chen, Y.-W. (2009). Development and cross-cultural application of a specific instrument to measure entrepreneurial intentions. Entrepreneurship Theory and Practice, 33(3), 593-617. http://dx.doi.org/10.1111/j.15406520.2009.00318.x

Liñán, F., Nabi, G., \& Krueger, N. (2013). British and spanish entrepreneurial intentions: A comparative study. Revista de Economía Mundial, 33, 73-103.

Manolova, T. S., Brush, C. G., \& Edelman, L. F. (2008). What do women entrepreneurs want? Strategic Change, 17(3-4), 69-82. http://dx.doi.org/10.1002/jsc. 817

Mau, W.-C. (2000). Cultural differences in career decision-making styles and selfefficacy. Journal of Vocational Behavior, 57(3), 365-378. http://dx.doi.org/ 10.1006/jvbe.1999.1745

Minniti, M., \& Arenius, P. (2003). Women in entrepreneurship. Paper presented at the Entrepreneurial Advantage of Nations: First Annual Global Entrepreneurship Symposium. , New York, NY.

Mueller, S. L. (2004). Gender gaps in potential for entrepreneurship across countries and cultures. Journal of Developmental Entrepreneurship, 9(3), 199-220.

Mueller, S. L., \& Thomas, A. S. (2001). Culture and entrepreneurial potential: A nine country study of locus of control and innovativeness. Journal of Business Venturing, 16(1), 51-75. doi: http://dx.doi.org/10.1016/S0883-9026(99)00039-7

Orobia, L., Sserwanga, A., \& Rooks, G. (2011). Risk taking and start-up capital: Exploring gender differences in uganda, through an international comparison. Journal of Economics and Behavioral Studies, 3(2), 83-93.

Podsakoff, P. M., MacKenzie, S. B., Lee, J. Y., \& Podsakoff, N. P. (2003). Common method biases in behavioral research: A critical review of the literature and recommended remedies. Journal of Applied Psychology, 88(5), 879-903. http://dx.doi.org/10.1037/0021-9010.88.5.879 
Pruett, M., Shinnar, R., Toney, B., Llopis, F., \& Fox, J. (2009). Explaining entrepreneurial intentions of university students: A cross-cultural study. International Journal of Entrepreneurial Behaviour \& Research, 15(6), 571-594. http://dx.doi.org/10.1108/13552550910995443

Sandhu, M. S., Sidique, S. F., \& Riaz, S. (2011). Entrepreneurship barriers and entrepreneurial inclination among malaysian postgraduate students. International Journal of Entrepreneurial Behaviour \& Research, 17(4), 428-449. http://dx.doi.org/10.1108/13552551111139656

Shane, S., Locke, E. A., \& Collins, C. J. (2003). Entrepreneurial motivation. Human Resource Management Review, 13(2), 257-279. http://dx.doi.org/10.1016/S10534822(03)00017-2

Shinnar, R. S., Giacomin, O., \& Janssen, F. (2012). Entrepreneurial perceptions and intentions: The role of gender and culture. Entrepreneurship Theory and Practice, 36(3), 465-493. http://dx.doi.org/10.1111/j.1540-6520.2012.00509.x

Swierczek, F. W., \& Ha, T. T. (2003). Entrepreneurial orientation, uncertainty avoidance and firm performance: An analysis of thai and vietnamese smes. The International Journal of Entrepreneurship and Innovation, 4(1), 46-58. http://dx.doi.org/10.5367/000000003101299393

Tambunan, T. (2009). Women entrepreneurship in asian developing countries: Their development and main constraints. Journal of Development and Agricultural Economics, 1(2), 27-40.

Thomas, A. S., \& Mueller, S. L. (2000). A case for comparative entrepreneurship: Assessing the relevance of culture. Journal of International Business Studies, 31(2), 287-301. http://dx.doi.org/10.1057/palgrave.jibs.8490906

van den Bos, K. (2009). Making sense of life: The existential self trying to deal with personal uncertainty. Psychological Inquiry, 20(4), 197-217. http://dx.doi.org/10.1080/10478400903333411

Verheul, I., Stel, A. V., \& Thurik, R. (2006). Explaining female and male entrepreneurship at the country level. Entrepreneurship and Regional Development, 18(2), 151-183. http://dx.doi.org/10.1080/08985620500532053

Wang, C. K., \& Wong, P.-K. (2004). Entrepreneurial interest of university students in singapore. Technovation, 24(2), 163-172. http://dx.doi.org/10.1016/S01664972(02)00016-0

Wennekers, S., Thurik, R., Stel, A., \& Noorderhaven, N. (2007). Uncertainty avoidance and the rate of business ownership across 21 oecd countries, 19762004. Journal of Evolutionary Economics, 17(2), 133-160. doi: 10.1007/s00191006-0045-1 
Wilson, F., Kickul, J., \& Marlino, D. (2007). Gender, entrepreneurial self-efficacy, and entrepreneurial career intentions: Implications for entrepreneurship education. Entrepreneurship Theory and Practice, 31(3), 387-406. http://dx.doi.org/10.1111/j.1540-6520.2007.00179.x

Zhao, H., Seibert, S. E., \& Hills, G. E. (2005). The mediating role of self-efficacy in the development of entrepreneurial intentions. Journal of Applied Psychology, 90(6), 1265-1272. http://dx.doi.org/10.1037/0021-9010.90.6.1265 